\title{
Zu Dramen Hugo von Hofmannsthals
}

\section{Analysen ihres historischen Gehaltes}

Dissertation

Zur Erlangung des Doktorgrades

der Philosophischen Fakultät

der Georg-August-Universität zu Göttingen

Vorgelegt von Gerhart Pickerodt aus Kassel Göttingen 1967 
Berichterstatter: Professor Dr. Peter Szondi

Mitberichterstatter: Professor Dr. Walther Killy

Tage der mündlichen Prüfung:

18. und 19. Juni 1968

ISBN 978-3-476-99650-3

ISBN 978-3-476-99649-7 (eBook)

DOI 10.1007/978-3-476-99649-7

Die vorliegende Dissertation ist unter dem Titel »Hofmannsthals Dramen. Kritik ihres historischen Gehalts« im Buchhandel erschienen.

(C) 1967 Springer-Verlag GmbH Deutschland

Ursprünglich erschienen bei J.B. Metzlersche Verlagsbuchhandlung 1967 
»O, wer einmal jemand anders sein könnte!

Nur 'ne Minute lang."

(Büchner, Leonce und Lena I,1)

»Keiner wird, was er nicht ist.«

(Hofmannsthal, Das Bergwerk zu Falun I) 


\section{Inhaltsübersicht}

Vorbemerkung . . . . . . . . . . . 9

I Gestern ................. 14

II Der Tod des Tizian . . . . . . . . . . . . 23

III Der Tor und der Tod . . . . . . . . . . . . . 34

IV Der weiße Fächer . . . . . . . . . . 46

V Die Frau im Fenster . . . . . . . . . . . . . . 58

VI Der Kaiser und die Hexe . . . . . . . . . . . . . . 74

VII Das Bergwerk zu Falun . . . . . . . . . . . . . . 93

VIII Der Abenteurer und die Sängerin . . . . . . . . 109

IX Das gerettete Venedig . . . . . . . . . . . . . 128

X Elektra .................. 151

XI Odipus und die Sphinx . . . . . . . . . . . . . . 172

XII Cristinas Heimreise . . . . . . . . . . . . . . . . . 198

XIII Der Schwierige . . . . . . . . . . . . . 213

XIV Der Unbestechliche . . . . . . . . . . . . 233

XV Der Turm . . . . . . . . . . . . . . 241

Literaturverzeichnis . . . . . . . . . . 269

Sachregister . . . . . . . . . . . . 273 